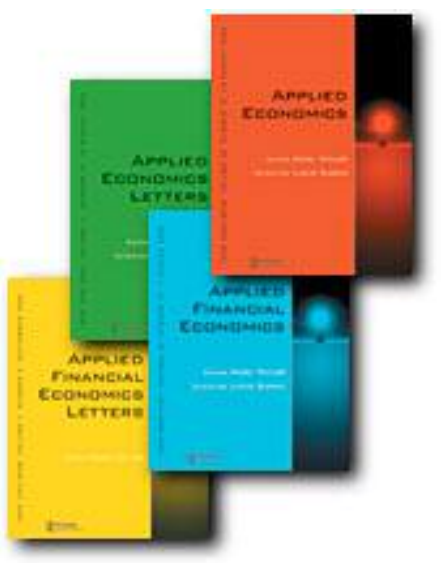

An Application of the DEA Double Bootstrap to Examine Sources of Efficiency in Bangladesh Rice Farming

\begin{tabular}{|r|l|}
\hline Journal: & Applied Economics \\
\hline Manuscript ID: & APE-06-0069.R1 \\
\hline Journal Selection: & Applied Economics \\
\hline JEL Code: & $\begin{array}{l}\text { C61 - Optimization Techniques|Programming Models|Dynamic } \\
\text { Analysis < C6 - Mathematical Methods and Programming }<\text { C - } \\
\text { Farm Firms, Farm Households, and Farm Input Markets }<\text { Q1 }- \\
\text { Agriculture }<\text { Q - Agricultural and Natural Resource Economics, D21 } \\
\text { - Firm Behavior }<\text { D2 - Production and Organizations }<\text { D - } \\
\text { Microeconomics }\end{array}$ \\
\hline Keywords: & DEA, Double bootstrap, Bangladesh, Rice Farms \\
\hline \hline
\end{tabular}

powersd by ScholarOne

Manuscript Central ${ }^{\text {TH }}$ 
An Application of the DEA Double Bootstrap to Examine Sources of Efficiency in Bangladesh Rice Farming

\author{
Kelvin Balcombe ${ }^{1}$, Iain Fraser ${ }^{2 \& 5 *}$, Laure Latruffe ${ }^{3}$, Mizanur Rahman ${ }^{4}$ and \\ Laurence Smith ${ }^{5}$ \\ 1 - Department of Agricultural and Food Economics \\ University of Reading \\ 2 - Applied Economics and Business Management \\ Kent Business School \\ University of Kent \\ 3 - INRA-Unité ESR Rennes
}

4 - Bangladesh Rice Research Institute, Gazipur 1701, Bangladesh

And

5 - Centre for Environmental Policy

Imperial College London

July 2006

*Address for Correspondence:

Applied Economics and Business Management

Kent Business School

University of Kent

Wye Campus

Wye

Kent, TN25 5AH

Tel: 02075942623

Email: I.M.Fraser@kent.ac.uk \& i.fraser@imperial.ac.uk 


\title{
An Application of the DEA Double Bootstrap to Examine Sources of Efficiency in Bangladesh Rice Farming
}

\begin{abstract}
In this paper we examine sources of technical efficiency for rice farming in Bangladesh. The motivation for the analysis is the need to close the rice yield gap to enable food security. We employ the DEA double bootstrap of Simar and Wilson (2006) to estimate and explain technical efficiency. This technique overcomes severe limitations inherent in using the two-stage DEA approach commonly employed in the efficiency literature. From a policy perspective our results show that potential efficiency gains to reduce the yield gap are greater than previously found. Statistically positive influences on technical efficiency are education, extension and credit, with age being a negative influence.
\end{abstract}

Key Words: DEA, double bootstrap, Bangladesh, rice farms

JEL Classification: C61, D21 and Q12

\section{Introduction}

Many papers in the agricultural economics literature that estimate farm level efficiency simultaneously attempt to explain the reasons for the existence of inefficiency. A commonly employed method is the two-step Data Envelopment Analysis (DEA) approach. First, estimates of farm level efficiency are produced, using the non-parametric DEA approach that constructs the efficient frontier with the best performing observations of the sample. These estimates are then regressed (e.g., Tobit) against a set of explanatory variables in an attempt to explain observed efficiency. Recent examples include Wadud and White (2000), Otsuki, et al. (2002), Coelli et al. (2002), Wadud (2003), Binam et al. (2003), Wu et al. (2003), Dhungana et al. (2004), Helfand and Levine (2004) and Chavas et al. (2005).

A recent methodological development by Simar and Wilson (2006) identifies serious limitations with the two-step DEA approach. They argue that the two-step procedure takes no account of the underlying data-generating process (DGP), casting doubt statistically on the meaning of the estimates produced to explain technical efficiency. Simar and Wilson argue that DEA efficiency estimates are serially correlated. As such standard inference approaches used in the conventional two-step DEA procedure are statistically invalid. These limitations lead them to develop the double bootstrap procedure that enables consistent inference within DEA models estimating and explaining efficiency scores, while simultaneously producing standard errors and confidence intervals for these efficiency scores. 
In this paper we employ the Simar and Wilson (2006) DEA double bootstrap procedure to estimate and explain technical efficiency for a sample of Bangladesh rice farms. The rationale for estimating the degree of technical inefficiency in Bangladesh farming can be traced to the apparent large gap between experiment stations' and highest 'profit maximising' yields achievable on farms.

In the efficiency literature shortfalls in yields relative to best practice are commonly attributed to socio-economic and institutional constraints and deficiencies in the management practices of farmers (De Datta et al., 1978). These reasons are frequently characterised by several stylised facts. First, rice producers are relatively older people with minimal formal education and limited extension service support, and assumed to be conservative and less receptive to new technology and practices. Second, farm size is very small and fragmented and much of the land is not cultivated by owners but by tenants with fewer resources and lower incentives for investment. Third, working capital in the form of credit is limited in availability. Four, much of the rice seed used is of poor quality and too infrequently replaced. Finally, many farmers are diverted from attention to farming by engagement in off-farm activities. These stylised facts suggest a potentially short term and practical solution of narrowing the yield gap by improving farm level efficiency and as such merit investigation and attention.

Our analysis adds to the literature that examines the efficiency of rice farming generally (e.g., Thiam et al., 2001) and in Bangladesh specifically (e.g., Banik, 1994; Sharif and Dar, 1996a,b; Wadud and White, 2000; Coelli et al., 2002; Wadud, 2003). Average DEA estimates of technical efficiency in the Bangladesh literature range between 0.66 (Coelli et al., 2002) and 0.91 (Wadud, 2003). Although all the studies indicate that there is a degree of technical inefficiency, the relative levels of technical inefficiency are not all markedly lower than those typically reported in studies of developed economy agriculture. Based on these results, the potential to close the yield gap may be less than anticipated. However, we need to be careful when attempting to draw broad policy implications from a specific set of related but independent studies. First, all estimates of technical efficiency are sample specific. This is then compounded by the fact that sample size and number of variables included in model 
specifications impact the estimates (Zhang and Bartels, 1998). In addition, it is now understood that DEA yields biased estimates of efficiency. Simar and Wilson (2000) explain that traditional DEA methods will yield sample estimates efficiency that will positively exaggerate the level of efficiency within a sample of data. By employing the double bootstrap DEA approach of Simar and Wilson (2006) we are able to report bias corrected estimates of technical efficiency. As a result of estimating the bias corrected measures of technical efficiency our results can be viewed by policy makers with increased confidence.

Several authors have also attempted to explain the sources of farm level efficiency using the DEA two-step approach. For example, Sharif and Dar (1996a,b) found that education was positively related to technical efficiency. In contrast Wadud and White (2000) found negative but statistically insignificant parameter estimates for education in terms of explaining efficiency. In addition they found that access to irrigation infrastructure defined as diesel-power and rural electrification yielded improvements in technical efficiency, whereas environmental degradation reduced it. Coelli et al. (2002) found few statistically significant estimates. This may have been the consequence of including too many explanatory variables and problems of collinearity, or for the reasons identified by Simar and Wilson (2006).

The structure of our paper is as follows. In Section 2 we explain and detail the double bootstrap methodology of Simar and Wilson (2006) that we employ this paper. Next we detail our farm survey instrument and sample data. Section 4 we present our results. Finally, in Section 5 we provide a summary and conclusions.

\section{DEA Estimation and the Double Bootstrap}

DEA estimation follows Simar and Wilson (2006) in that we estimate their outputorientated double bootstrap specification. The output-orientated DEA efficiency estimator $\hat{\theta}_{i}$ for any data point $\left(x_{i}, y_{i}\right)$, where $y$ and $x$ are observed outputs and inputs and $i=1 \ldots \ldots, n$ is the specific farm, is derived by solving the following linear program:

$$
\hat{\theta}_{i}=\max \left\{\theta>0 \mid \theta y_{i} \leq \sum_{i=1}^{n} \gamma_{i} y_{i} ; x_{i} \geq \sum_{i=1}^{n} \gamma_{i} x_{i} ; \sum_{i=1}^{n} \gamma_{i}=1 ; \gamma_{i} \geq 0, i=1, \ldots \ldots . n\right\}
$$


where $1 \leq \hat{\theta}_{i}$. When $\hat{\theta}_{i}=1$ farms are technically efficient, and they are inefficient when $\hat{\theta}_{i}>1$. $\hat{\theta}_{i}-1$ is the proportional increase in outputs that could be achieved by the $i$-th farm with input quantities held constant, and $\gamma$ is a non-negative intensity variable used to scale individual observed activities for constructing the piecewise linear technology.

Two points can be noted about Equation (1). First, the DEA progam given by Equation (1) assumes variable returns to scale (VRS), but we can impose constant returns to scale (CRS) by removing the constraint $\sum_{i=1}^{n} \gamma_{i}=1$ from this program. Second, Simar and Wilson (2000) observe that $\hat{\theta}_{i}$ is a downward biased estimator of $\theta_{i}$, as the farms that determine the frontier in reality might not be included in the sample at hand, and hence farms' potential output increase might be in fact larger than revealed by this DEA program.

The efficiency estimates we generate in this study are $\hat{\theta}_{i}$ where $\hat{\theta}_{i}-1$ represents the potential output expansion. These estimates that are truncated below 1 are typically employed as the dependent variable in the step two, namely truncated maximum likelihood regression on the following model:

$$
\hat{\theta}_{i}=z_{i} \beta+\varepsilon_{i} \geq 1
$$

where $z_{i}$ is a vector of variables assumed to impact on the choice and use of $y$ and $x, \beta$ is a vector of parameters to be estimated, and $\varepsilon_{i}$ is a continuous iid random variable, distributed $\mathrm{N}\left(0, \sigma_{\varepsilon}^{2}\right)$ with left-truncation at $1-z_{i} \beta$ for each $i$, and assumed independent of $z_{i}$.

\subsection{The Double Bootstrap}

The reason why bootstrap procedures are adopted by Simar and Wilson $(2000,2006)$ is because very few results exist for the sampling distributions of interest. The idea behind bootstrapping is simply to simulate the sampling distribution of interest by mimicking the DGP. The DGP that provides the rationale for the Simar and Wilson (2006) double bootstrap is the DEA model described by Equation (1) and the step two 
truncated regression represented by Equation (2) and typically used to explain efficiency.

To implement the bootstrap procedure we assume that the original sample data is generated by the DGP and that we are able to simulate the DGP by taking a 'new' or pseudo data set that is drawn from the original data set. We then re-estimate the DEA model with this 'new' data. By repeating this process many times we are able to derive an empirical distribution of these bootstrap values that gives a Monte Carlo approximation of the sampling distribution and facilitates inference procedures. The performance of the bootstrapping methodology and the reliability of the statistical inference crucially depends on how well it characterises the true DGP and on the accuracy of the re-sampling simulation to copy the DGP.

The procedure we employ in this paper is referred to as Algorithm 2 by Simar and Wilson (2006). They also present an alternative double bootstrap procedure but their Monte Carlo results lead them to advocate use of Algorithm 2. Algorithm 2 consists of the following seven steps with two sub-routine loops embedded within:

Step 1 - Estimate DEA output-orientated efficiency scores $\hat{\theta}_{i}$ for all farms in the sample data employing Equation (1).

Step 2 - Equation (2) is estimated by employing truncated maximum likelihood yielding estimates $\hat{\beta}$ and $\hat{\sigma}_{\varepsilon}$.

Step 3 - For each $i=1, \ldots n$, repeat the following 4 steps (i-iv) $L_{1}$ times to yield a set of bootstrap estimates $\mathrm{B}_{i}=\left\{\hat{\theta}_{i b}^{*}\right\}_{b=1}^{L_{1}}$.

i) For each $i=1, \ldots, n, \varepsilon_{\mathrm{i}}$ is drawn from the $\mathrm{N}\left(0, \hat{\sigma}_{\varepsilon}\right)$.

ii) For each $i=1, \ldots, n$, compute $\theta_{i}^{*}=z_{i} \hat{\beta}+\varepsilon_{\mathrm{i}}$. 
iii) Construct a pseudo data set $\left(x_{i}^{*}, y_{i}^{*}\right)$ where $x_{i}^{*}=x_{i}$ and $y_{i}^{*}=y_{i}\left(\hat{\theta}_{i} / \theta_{i}^{*}\right)$

iv) Using the pseudo data set and Equation (1), compute pseudo efficiency estimates $\hat{\theta}_{i}^{*}$ for all $i=1, \ldots, n$.

Step 4 - For each farm $i=1, \ldots, n$, compute the bias-corrected estimator $\hat{\hat{\theta}}_{\mathrm{i}}$ as $\hat{\hat{\theta}}_{\mathrm{i}}=\hat{\theta}_{\mathrm{i}}-\operatorname{Bias}\left(\hat{\theta}_{\mathrm{i}}\right)$ where the bias term is estimated by following Simar and Wilson (2000) as follows: $\left(\frac{1}{\mathrm{~L}_{1}} \sum_{\mathrm{b}=1}^{\mathrm{L}_{1}} \hat{\theta}_{i b}^{*}\right)-\hat{\theta}_{\mathrm{i}}$.

Step 5 - Employing truncated maximum likelihood, regress $\hat{\hat{\theta}}_{\mathrm{i}}$ on $z_{i}$ to yield estimates $\hat{\hat{\beta}}$ and $\hat{\sigma}_{\varepsilon}$.

Step 6 - Repeat the following three steps (i-iii) $L_{2}$ times yielding a set of bootstrap estimates $\Gamma=\left\{\left(\hat{\hat{\beta}}^{*}, \hat{\hat{\sigma}}_{\varepsilon}^{*}\right)_{b}\right\}_{b=1}^{L_{2}}$.

i) For each farm $i=1, \ldots, n, \varepsilon_{\mathrm{i}}$ is drawn from the $\mathrm{N}\left(0, \hat{\hat{\sigma}}_{\varepsilon}\right)$ distribution.

ii) For each farm $i=1, \ldots, n$, compute $\theta_{\mathrm{i}}^{* *}=z_{i} \hat{\hat{\beta}}+\varepsilon_{\mathrm{i}}$.

iii) Employing truncated maximum likelihood, regress $\theta_{i}^{* *}$ on $z_{i}$ to yield estimates $\hat{\hat{\beta}} *$ and $\hat{\hat{\sigma}}_{\varepsilon}^{*}$.

Step 7 - Use the bootstrap estimates $\Gamma$ and the estimates $\hat{\hat{\beta}}$ and $\hat{\sigma}_{\varepsilon}$ generated in Step 5 to construct confidence intervals for each element of $\beta$ and $\sigma_{\varepsilon}$. The $(1-\alpha)$ per cent confidence interval of the $j$ th element of vector $\beta$, where $\alpha$ is some small value (i.e., $\alpha=0.05$ ) and $0<\alpha<1$, is constructed as the 
$\operatorname{Pr}\left(-\mathrm{b}_{\alpha / 2} \leq \hat{\hat{\beta}}_{\mathrm{j}}^{*}-\hat{\hat{\beta}}_{\mathrm{j}} \leq-\mathrm{a}_{\alpha / 2}\right) \approx 1-\alpha$ such that the estimated confidence interval is $\left[\hat{\hat{\beta}}_{j}+a_{\alpha / 2}^{*}, \hat{\hat{\beta}}_{j}+b_{\alpha / 2}^{*}\right]$. This is the same method applied to construct confidence intervals for the efficiency scores introduced by Simar and Wilson (2000).

\section{Survey Design and Sample Data}

As many farmers in Bangladesh are illiterate and there are minimal written records, to minimise errors arising from farmer recall, data was collected immediately after the “aman" harvest, in late November and early December. In total 295 observations were collected, with data collection concentrating on farms that transplanted their crop following manual cultivation and that did not use supplementary irrigation, therefore ensuring a relatively homogenous sample.

Data was collected on output, inputs and a range of socio-economic variables selection of socio-economic variables - given existing literature informed choice. The output measured was rice in kilograms, comprising quantities sold and kept for own use (consumption and seeds). All main production system inputs (five in total) were measured. A key input into the production process in this region of Bangladesh is bullock labour. This is because bullocks are still a major source of draft power for ploughing and harrowing during seedbed preparation. We assumed that a bullock 'pair-day' equates to a pair of bullocks working 6 hours a day. Human labour input is measured as the number of man-days for various activities and it includes all hired and family labour, assuming that 1 day consists of 8 hours work. Seed is measured as the physical quantity of seeds in kilograms, comprising that purchased and that produced on-farm. The amount of fertiliser is measured as kilograms applied and includes urea, triple super phosphate, murate of potash and compost based on the active ingredient. Finally, land area devoted to rice production is measured in hectares.

Data was also collected for farmer-specific socio-economic variables. The variables used in our analysis to explain technical efficiency include the farmers' age (years), 
whether they have had any formal education (binary), their interaction with extension services (binary), their land tenure (i.e., tenant farmer or owner), their ability to gain credit (binary), whether off-farm income was earned (binary), and total farm area as a farm size variable. We would have preferred to have collected continuous data for several of the binary variables but it proved difficult to construct meaningful measures that could be used in the analysis. Descriptive statistics for the sample data are presented in Table 1.

\section{\{Approximate Position of Table 1\}}

\section{Estimation and Results}

We estimate and present results for CRS and VRS double bootstrap DEA specifications. For both specifications we have employed 2,500 bootstrap iterations, which is sufficient to be confident in the results produced. All models were estimated using GAUSS Version 5.0.

\subsection{Point and Interval Estimates of Technical Efficiency}

We begin by reporting sample average point and interval estimates of technical efficiency in Table 2. It should be noted that Table 2 does not display the summary measures of the output-orientated technical efficiency scores $\left(\hat{\theta}_{i}\right)$ as such. As is the convention, the inverse of these output-orientated scores were computed for ease of reading.

\section{\{Approximate Position of Table 2\}}

Results in Table 2 show that within the sample studied, there is a non-negligible potential efficiency improvement in terms of output increase while keeping the level of input constant. Indeed for the VRS specification average technical efficiency (0.59) is lower than previously reported by any existing studies. However, it needs to be remembered that these are bias corrected estimates and as such it makes a direct comparison with existing estimates in the literature difficult.

Unlike the existing papers in the literature on Bangladesh rice farming, we also provide interval estimates of technical efficiency. As can be seen from Table 2 on average point estimates of technical efficiency have a 0.1 interval for a $95 \%$ 
confidence interval. However, for those farms that are more efficient in our sample the $95 \%$ confidence interval is significantly wider as illustrated by the minimum and maximum results for both CRS and VRS. Even with this widening of the interval the double bootstrap DEA model employed in this paper yields reasonably narrow confidence intervals compared to existing DEA interval estimates reported in the literature (e.g., Brümmer, 2001 and Latruffe et al., 2005). This is an important result because a criticism that has arisen as a result of DEA confidence interval estimation is that, when we take account of sampling error, our power to discern differences in relative levels of technical efficiency is significantly weakened. By narrowing the width of the confidence interval the applied researcher is in a stronger position statistically to identify specific groups of farms in terms of relative efficiency. In the case of agricultural research, this is a particularly important finding if the purpose of applied frontier estimation is to help identify best and worst performing farms as part of an extension exercise.

Given the above qualifications, from a policy perspective the point estimates of technical efficiency reported here indicate that there is significant room for improvement in technical efficiency as a means to make up the yield gap that exists in Bangladesh agriculture. As such it would appear sensible to examine what the determinants of technical efficiency in our sample of farms might be.

\subsection{Explaining Technical Efficiency}

We now turn to our results that attempt to explain sources of technical efficiency. Following Simar and Wilson (2006) a positive sign on an explanatory variable indicates an obstacle to efficiency while a negative sign indicates a positive influence on efficiency. To assess the statistical significance of our results we report standard errors and 95\% confidence intervals. These results are presented in Table 3.

\section{\{Approximate Position of Table 3\}}

Our estimation reveals some interesting findings especially when compared to the existing literature on Bangladesh rice farming. First, Age has a negative impact on technical efficiency, a finding in keeping with Wadud and White (2000). That is older farmers are more likely to be technically inefficient. Our estimate is statistically 
significant for the CRS specification being within the 95 percent confidence interval. It is also the case for the VRS specification that the estimate is within a 90 percent confidence interval.

Next we find that Education is statistically significant for both VRS and CRS specification and that it is positively related to a farm being technically efficient. In previous research using the conventional two-step procedure Coelli et al. (2002) found education to have a positive effect on technical efficiency albeit their findings are statistically insignificant. In contrast Wadud and White (2000) report the opposite effect although it is statistically insignificant.

The third explanatory variable is Extension. We can see that for both specifications Extension is statistically significant and positively related to higher levels of technical efficiency. The statistical significance of our finding is in contrast to the result reported by Coelli et al (2002).

The Ownership variable proved to be positively related to technical efficiency in both specifications albeit statistically insignificant. A positive relationship between owneroperators and efficiency has previously been identified by Coelli et al. (2002) although in that study it was in terms of cost efficiency only.

In the case of Credit we found a positive relationship with technical efficiency. This estimate is statistically significant for the CRS being within the 95 percent confidence interval. It is also the case for the VRS specification that the estimate is within a 90 percent confidence interval. Neither Coelli et al. (2002) or Wadud and White (2000) include a measure of credit in their model.

Next we see that Off-Farm activity has a negative impact on technical efficiency. However, for both specifications the estimate is statistically very weak. The statistical weakness of this finding is in contrasts to Coelli et al. (2002) who find strong statistical evidence for a negative impact of off-farm work. It is very likely that this result stems from the binary nature of the variable we employ. Coelli et al. used a much richer measure of off-farm income. 
The final variable we report is total farm area. For both specifications we find a positive relationship between farm size and technical efficiency. This is in line with the findings reported by Wadud and White (2000). However, for both specifications reported here the estimates are statistically insignificant as is the case in Wadud and White.

So in summary being educated, having access to extension services, owner-operated, having credit available and having a larger farm, are all associated with a farm being technically efficient. The only variables that are positively related to output-orientated technical efficiency, and hence that hampers farm performance, are farmer's age and earning off-farm income.

\section{Discussion and Conclusions}

In this paper we have employed the DEA double bootstrap procedure of Simar and Wilson (2006) to examine estimates and explain sources of technical efficiency for a sample of rice farmers in Bangladesh. From a policy perspective there are two important findings.

First, this study has revealed that there is substantial room for improvements in technical efficiency in the sample of farms analysed. The potential improvement, albeit difficult to directly compare with existing estimates in the literature, is almost certainly bigger than previous research has revealed using DEA. Indeed it would be interesting to investigate the extent to which previous estimates of technical efficiency would need to be revised. As a result improvements in technical efficiency amongst these farmers can help to reduce the existing yield gap between the most and the least efficient farmers.

Second, the analysis revealed factors that enhance technical efficiency to be education, extension services, owner-operated farms, availability of credit and bigger farms. Although these factors had been identified in earlier research we can, as a result of the methods employed in this paper, feel very secure in presenting these findings. Similarly, we have identified that age and off-farm activity as being negatively related to technical efficiency. The results reported here suggest that access to technical information and to credit, are the leading constraints to improved 
productivity in Bangladesh rice farming. Also that attempts to alleviate these constraints are likely to be more effective when targeted at younger and bettereducated farmers or perhaps farm family members.

Finally, it can be stressed once again that the developments in DEA methodology examined in this paper have been applied by only very few researchers to date. There is clearly a need for greater adoption and consideration of the methods employed here to provide increased insight into their potential. Although our findings do not contradict previous studies, it is advisable to use the Simar and Wilson (2006) double bootstrap procedure in further applied research on technical efficiency, as it can increase the confidence that policy makers can place on results generated. 


\section{References}

Banik, A. (1994). Technical Efficiency of Irrigated Farms in a Village of Bangladesh. Indian Journal Agricultural Economics 49(1): 70-78.

Binam, J.N., K. Sylla, I. Diarra and G. Nyambi (2003). Factors Affecting Technical Efficiency Among Coffee Farmers in Cote d'Ivoire: Evidence from the centre West Region, African Development Review, 15(1): 66-76.

Brümmer, B. (2001). Estimating Confidence Intervals for Technical Efficiency: The Case of Private Farms in Slovenia. European Review of Agricultural Economics 28(3), 285-306.

Chavas, J.P., Petrie, R. and Roth, M. (2005). Farm Household Production Efficiency: Evidence from the Gambia, American Journal of Agricultural Economics, 87(1): 160179.

Coelli, T. J., S. Rahman and C. Thirtle (2002). Technical, Allocative, Cost and Scale Efficiencies in Bangladesh Rice Cultivation: A Non-Parametric Approach. Journal of Agricultural Economics 33(3): 605-624.

De Datta, S. K., Gomez, K., Herdt, R. W., and Barker, R. (1978). " A Handbook on the Methodology for an Integrated Experiment on Rice Yield Constraints." International Rice Research Institute, Los Baños, Philipines.

Dhungana, B.R., Nuthall, P.L. and Nartea, G.V. (2004). Measuring the Economic Inefficiency of Nepalese Rice farms Using Data Envelopment Analysis, Australian Journal of Agricultural and Resource Economics, 48: 347-370.

Helfand, S.M. and Levine, E.S. (2004). Farm Size and the Determinants of Productive Efficiency in the Brazilian Center-West, Agricultural Economics, 31: 241-249.

Latruffe, L., Balcombe, K., Davidova S. and Zawalinska, K. (2005). Technical and Scale Efficiency of Crop and Livestock Farms in Poland: Does Specialisation Matter? Agricultural Economics, 32: 281-296.

Otsuki, T., I.W. Hardie and E.J. Reis (2002). The Implication of Property Rights for Joint Agriculture-Timber Productivity in the Brazilian Amazon, Environment and Development Economics, 7(2): 299-323.

Rahman, M. (2003) The Application of Frontier Approaches to Model the Efficiency of Rice Producers in Bangladesh, Phd Thesis, Imperial College London, Wye campus, Ashford, Kent, UK.

Sharif, N. R. and A. A. Dar (1996a). An Empirical Study of the Patterns and Sources of Technical Inefficiency in Traditional and HYV Rice Cultivation in Bangladesh. Journal of Development Studies 32(4): 612-629.

Sharif, N.R. and A.A. Dar (1996b). Stochastic Frontiers and Technical Efficiency Distributions: An Analysis Based on Rice Farming Data for Bangladesh, Canadian Journal of Economics, 45: s582-s586. 
Simar, L. and Wilson, P. (2000). Statistical Inference in Nonparametric Frontier Models: The State of the Art. Journal of Productivity Analysis 13(1), 49-78.

Simar, L. and Wilson, P. (2006). Estimation and Inference in Two-Stage, SemiParametric Models of Production Processes, Journal of Econometrics, (Forthcoming).

Thiam, A., B.E. Bravo-Ureta and T.E. Rivas (2001). Technical Efficiency in Developing Country Agriculture: A Meta-Analysis, Agricultural Economics, 25: 235243.

Wadud, M.A. (2003). Technical, Allocative, and Economic Efficiency of Farms in Bangladesh: A Stochastic Frontier and DEA Approach, Journal of Developing Areas, 37(1): 109-126.

Wadud, A. and B. White (2000). Farm Household Efficiency in Bangladesh: A Comparison of Stochastic Frontier and DEA Methods. Applied Economics 32: 16651673.

Wu, S., S. Devadoss and Y. Lu (2003). Estimation and Decomposition of Technical Efficiency for Sugarbeet Farms, Applied Economics, 35 (4): 471-484.

Zhang, Y. and R. Bartels (1998). The Effect of Sample Size on the Mean Efficiency in DEA with an Application to Electricity Distribution in Australia, Sweden and New Zealand, Journal of Productivity Analysis, 9, 187-204. 
Table 1: Descriptive Statistics of Sample Data

\begin{tabular}{|c|c|c|c|c|c|}
\hline & Unit & Mean & $\begin{array}{l}\text { Standard } \\
\text { Deviation }\end{array}$ & Minimum & Maximum \\
\hline \multicolumn{6}{|l|}{ DEA Variables } \\
\hline Rice produced & $\mathrm{Kg}$ & $2,578.7$ & 430.23 & $1,481.5$ & $4,065.5$ \\
\hline Bullock Labour & Pair & 29.30 & 3.65 & 20.00 & 41.54 \\
\hline Human Labour & Man-days & 106.15 & 13.14 & 73.85 & 149.23 \\
\hline Seed & $\mathrm{Kg}$ & 50.28 & 6.88 & 30.77 & 69.23 \\
\hline Fertiliser & $\mathrm{Kg}$ & 471.97 & 520.2 & 38.46 & $1,512.3$ \\
\hline Rice area & Hectares & 0.68 & 0.36 & 0.06 & 2.33 \\
\hline \multicolumn{6}{|l|}{$\begin{array}{l}\text { Socio-Economic } \\
\text { Variables }\end{array}$} \\
\hline Age & Years & 45.4 & 10.38 & 18 & 70 \\
\hline Education & Binary & .66 & .48 & 0 & 1 \\
\hline Extension & Binary & .34 & .47 & 0 & 1 \\
\hline Ownership & Binary & .26 & .44 & 0 & 1 \\
\hline Credit & Binary & .37 & .48 & 0 & 1 \\
\hline Off-farm Income & Binary & .50 & .48 & 0 & 1 \\
\hline Total farm area & Hectares & 6.38 & 3.22 & 1.87 & 37 \\
\hline
\end{tabular}


Table 2: Summary Measures of Technical Efficiency

\begin{tabular}{|c|c|c|c|c|c|c|}
\hline & \multicolumn{3}{|l|}{ CRS } & \multicolumn{3}{|l|}{ VRS } \\
\hline & Average & $\begin{array}{l}95 \% \\
\text { Confidence } \\
\text { Interval } \\
\text { Lower }\end{array}$ & $\begin{array}{l}95 \% \\
\text { Confidence } \\
\text { Interval } \\
\text { Upper }\end{array}$ & Average & $\begin{array}{l}95 \% \\
\text { Confidence } \\
\text { Interval } \\
\text { Lower }\end{array}$ & $\begin{array}{l}95 \% \\
\text { Confidence } \\
\text { Interval } \\
\text { Upper }\end{array}$ \\
\hline Mean & 0.64 & 0.57 & 0.69 & 0.59 & 0.53 & 0.63 \\
\hline Median & 0.63 & 0.57 & 0.67 & 0.58 & 0.54 & 0.62 \\
\hline Mode & 0.54 & 0.68 & 0.99 & 0.57 & 0.54 & 0.58 \\
\hline Standard & & & & & & \\
\hline Deviation & 0.10 & 0.07 & 0.13 & 0.08 & 0.07 & 0.09 \\
\hline Range & 0.45 & 0.33 & 0.56 & 0.44 & 0.33 & 0.57 \\
\hline Minimum & 0.40 & 0.36 & 0.43 & 0.38 & 0.35 & 0.41 \\
\hline Maximum & 0.85 & 0.69 & 0.99 & 0.82 & 0.67 & 0.98 \\
\hline
\end{tabular}


Table 3: Sources of Technical Efficiency (Number of Bootstrap Iterations 2,500)

\begin{tabular}{|c|cccc|}
\hline \multicolumn{5}{|c|}{ VRS } \\
\hline & Parameter & Std Error & $\begin{array}{c}\text { Lower } \\
\mathbf{9 5 \%} \text { C I }\end{array}$ & $\begin{array}{c}\text { Upper } \\
\mathbf{9 5 \% ~ C ~ I ~}\end{array}$ \\
\hline Intercept & 0.51 & 0.23 & 0.96 & 0.05 \\
Age & 0.95 & 0.57 & 2.06 & -0.16 \\
Education & -0.88 & 0.29 & -0.31 & -1.44 \\
Extension & -1.06 & 0.31 & -0.45 & -1.67 \\
Ownership & -0.37 & 0.30 & 0.22 & -0.97 \\
Credit & -0.47 & 0.29 & 0.10 & -1.04 \\
Off farm & 0.19 & 0.26 & 0.69 & -0.31 \\
Area & -0.06 & 0.28 & 0.49 & -0.62 \\
\hline & & & & \\
& & CRS & & \\
\hline \multicolumn{7}{|c}{} & & Lower & Upper \\
Intercept & 0.23 & 0.23 & 0.69 & -0.23 \\
Age & 1.35 & 0.57 & 2.46 & 0.24 \\
Education & -0.79 & 0.29 & -0.23 & -1.35 \\
Extension & -0.89 & 0.33 & -0.24 & -1.53 \\
Ownership & -0.19 & 0.31 & 0.41 & -0.79 \\
Credit & -0.74 & 0.30 & -0.16 & -1.33 \\
Off farm & 0.01 & 0.27 & 0.54 & -0.51 \\
Area & -0.10 & 0.28 & 0.46 & -0.66 \\
\hline
\end{tabular}

